\title{
Ryo Okui awarded the 2020 Japanese Economic Association Nakahara Prize
}

\author{
Mototsugu Shintani ${ }^{1}$
}

(c) Japanese Economic Association 2021

The Japanese Economic Association (JEA) Nakahara Prize was created in 1995 with a donation from Mr. Nobuyuki Nakahara. The prize was established to honour researchers in economics under the age of 45 who have made significant contributions that are internationally recognized.

It is a great pleasure to announce that the 2020 JEA Nakahara Prize has been awarded to Professor Ryo Okui, for his contribution to theoretical econometrics related to the choice of optimal instruments under many moment conditions. Born in 1975, Professor Okui earned a bachelor's degree in Economics from Kyoto University in 1998, a master's degree in Economics from Kyoto University in 2000, and a Ph.D. in Economics from the University of Pennsylvania in 2005. He is currently an Associate Professor of Economics at Seoul National University. Professor Okui works in the research field of econometric theory, which is centered on micro econometrics and panel data analysis, as well as in the field of experimental economics.

First, in a series of papers, Professor Okui examines the choice of optimal instrumental variables in the context of bias-variance trade-offs by approximating mean squared errors (MSE) of instrumental variables estimators in an environment where many possible instrumental variables are available. Okui (2009) considers a model of dynamic panel data, and it is the very first paper that has derived MSE in such models. Although the contribution is theoretical, his finding can be used in applied research in which panel data is used. Okui (2011) and Kuersteiner and Okui (2010) both use cross-sectional models. In particular, the latter uses a more general way of combining instrumental variables, presenting a widely applicable method of constructing the optimal instrumental variables. There is no doubt that this paper is one of those at the frontier in the study of models with many instruments.

Second, Hossain and Okui (2013) are cited extensively in the field of experimental economics. The paper presents a potential solution to how one should elicit belief about the distribution of random variables in an experimental setting. It is a

Mototsugu Shintani

shintani@e.u-tokyo.ac.jp

1 Faculty of Economics, The University of Tokyo, Tokyo, Japan 
theoretical contribution with an important implication for applications, such as how one should design a question about expectations.

These significant contributions by Professor Okui have led the selection committee to award him the 2020 Nakahara Prize.

Selection committee

Mototsugu Shintani, The University of Tokyo (Chair)

Anton Braun, Federal Reserve Bank of Atlanta

Federico Echenique, California Institute of Technology

Hidehiko Ichimura, The University of Arizona and the University of Tokyo

Atsushi Kajii, Kwansei Gakuin University

Yuichi Kitamura, Yale University

Sagiri Kitao, The University of Tokyo

\section{References}

Hossain, T., \& Okui, R. (2013). The binarized scoring rule. Review of Economic Studies, 80(3), 984-1001.

Okui, R. (2009). The optimal choice of moments in dynamic panel data models. Journal of Econometrics, 151(1), 1-16.

Okui, R. (2011). Instrumental variable estimation in the presence of many moment conditions. Journal of Econometrics, 165(1), 70-86.

Okui, R., \& Kuersteiner, G. (2010). Constructing optimal instruments by first-stage prediction averaging. Econometrica, 78(2), 697-718. 